\title{
Effects of co-habitation between Anopheles gambiae s.s. and Culex quinquefasciatus aquatic stages on life history traits
}

Eliningaya J Kweka ${ }^{1,2^{*}}$, Goufa Zhou ${ }^{3}$, Leila B Beilhe ${ }^{1}$, Amruta Dixit ${ }^{3}$, Yaw Afrane ${ }^{1}$, Thomas M Gilbreath III', Stephen Munga', Mramba Nyindo ${ }^{1}$, Andrew K Githeko ${ }^{1}$ and Guiyun Yan ${ }^{3}$

\begin{abstract}
Background: The effective measures for the control of malaria and filariasis vectors can be achieved by targeting immature stages of anopheline and culicine mosquitoes in productive habitat. To design this strategy, the mechanisms (like biotic interactions with conspecifc and heterospecific larvae) regulating mosquito aquatic stages survivorship, development time and the size of emerging adults should be understood. This study explored the effect of co-habitation between An. gambiae s.s. and Cx. quinquefasciatus on different life history traits of both species under different densities and constant food supply in the habitats of the same size under semi-natural conditions.
\end{abstract}

Methods: Experiments were set up with three combinations; Cx. quinquefasciatus alone (single species treatment), An. gambiae s.s. alone (single species treatment); and An. gambiae s.s. with Cx. quiquefasciatus (co-habitation treatment) in different densities in semi field situation.

Results: The effect of co-habitation of An. gambiae s.s. and CX. quinquefasciatus was found to principally affect three parameters. The wing-lengths (a proxy measure of body size) of An. gambiae s.s. in co-habitation treatments were significantly shorter in both females and males than in An. gambiae s.s single species treatments. In CX. quinquefasciatus, no significant differences in wing-length were observed between the single species and cohabitation treatments. Daily survival rates were not significantly different between co-habitation and single species treatments for both An. gambiae s.s. and Cx. quinquefasciatus. Developmental time was found to be significantly different with single species treatments developing better than co-habitation treatments. Sex ratio was found to be significantly different from the proportion of 0.5 among single and co-habitation treatments species at different densities. Single species treatments had more males than females emerging while in co-habitation treatments more females emerged than males. In this study, there was no significant competitive survival advantage in cohabitation.

Conclusion: These results suggest that co-habitation of An. gambiae s.s. and Cx. quinquefasciatus in semi-natural conditions affect mostly An. gambiae s.s. body size. Hence, more has to be understood on the effects of cohabitation of An. gambiae s.s. and CX. quinquefasciatus in a natural ecology and its possible consequences in malaria and filariasis epidemiology.

\footnotetext{
* Correspondence: pat.kweka@gmail.com

${ }^{1}$ Centre for Global Health Research, Kenya Medical Research Institute, P. O.

Box 1578, Kisumu 40100, Kenya

Full list of author information is available at the end of the article
} 


\section{Background}

Mosquito breeding habitats vary due to multiple factors such as physico-chemical characteristics of habitats, habitat type and size and predator abundance [1-6]. In African mosquito ecology, immature stages of Anopheles gambiae s.s. and Culex quinquefasciatus are frequently found to co-occur in diverse habitats such as drainage ditches, swamps and abandoned goldmines [7-11]. In mosquito species, such as An. gambiae, An. stephensi, Aedes aegypti, and $C x$. pipiens, the effects of both abiotic and biotic factors on immatures have been documented to have an influence on life history traits and subsequent adult fitness [12,13].

In population and community ecology, predation, density (experienced mainly under intraspecific interaction), interspecific interactions, and nutrient dependencies are the main mechanisms that regulate population dynamics $[3,14,15]$. Mosquito populations respond to unfavorable conditions with a drop in one or more vital rates, usually in growth rate and survivorship, but also in fecundity and recruitment [16]. In Ae. aegypti and Ae. albopictus, density dependence is generally a major component of larval mortality [16]. In these species, density dependence is mostly driven by exploitation competition rather than interference competition $[17,18]$. Improving the knowledge on density dependence is crucial in determining the ultimate outcome of larval control strategies. Interspecific competition can be a major determinant of species distribution and ultimately of community structure, this phenomenon is widespread among insects [19-21]. Interspecific competition that can be investigated with co-habitation species could lead in some cases to competitive displacement of local population [20,21]; based upon certain ecological principles that state that different species cannot simultaneously occupy the same niche.

Some studies investigating coexistence of the different species under laboratory conditions revealed the existence of predation and cannibalism between species. In An. gambiae s.s. (Gilles) and An. quadrannulatus (Theobald) co-occurrence, fourth instar larvae of both species were predacious and cannibalistic towards the first and second instar larvae [22]. In another study with An. arabiensis (Patton) and An. gambiae (Gilles) larvae, cannibalism and predation occurred as a result of maximum interaction in small aquatic habitats and not due to food deprivation [23]. Muturi et al. found that predation and cannibalism in co-habitation of An. gambiae s.s. and Cx. quinquefaciatus happened only between first and third instars of An. gambiae and Cx. quinquefasciatus when they shared the same habitat [5]. There was no predation effect observed in larvae of An. gambiae s.s. and $C x$. quinquefasciatus of the same age structure [5].
Predatory behaviour has also been found in other species. For example, Toxorhynchites spp. have been shown to prey on different mosquito species [24-27]. Culex (Lutzia) fuscanus (Wiedemann) were predators of several mosquito species such as An. stephensi [28], Ae. albopictus, and Cx. quinquefasciatus [29].

In previous studies on Cx. pipiens and An. gambiae s. l., the effect of the factors cited above affecting mosquito dynamics have been widely investigated and little attention has been given to the effect on life history traits such as survivorship, developmental time, sex ratio and wing-length [14,15,30-32]. Predation, coexistence and interspecific competition between An. gambiae s.s. and $C x$. quinquefasciatus larvae may lead to survival rate reduction, developmental time increase, sex ratio distortion and body size reduction which might be a factor altering the fitness of emerging adults and the diseasetransmitting ability of one or both species [33-35]. Examination of the wing length variation in the natural population of malaria vectors have been conducted elsewhere [33-36]; but the mosquito species composition was not considered to underscore the observed effect on adult wing-length. The effects of co-habitation between An. gambiae s.s. and Cx. quinquefasciatus are not clearly known when the larvae experience different densities in a habitat containing the same amount of resources.

Therefore, the objectives of this study were to investigate effects of co-habitation between An. gambiae s.s. and $C x$. quinquefasciatus on different life history traits in semi-natural microcosm experiments. We investigated the downstream effects on survivorship, winglength, development time, and sex ratio in co-habitation species.

\section{Methods}

\section{Mosquito collection and rearing}

An. gambiae s.s. gravid females were aspirated indoors from Iguhu village in the western Kenya highlands. The gravid females were reared singly in a paper cup covered with netting material placed in an insectary maintained at $28.4 \pm 1^{\circ} \mathrm{C}$ and relative humidity of 70 to $80 \%$. The light regime was L 12: D 12 . These females were provided with sugar solution (10\% sucrose). Eggs laid were collected on wet filter papers and kept in an incubator for 48 hours before hatching. After egg-laying, all females of $A n$. gambiae s.l. were taken for polymerase chain reaction to confirm species identification as $A n$. gambiae s.s., as described by Scott et al., [37]. The eggs of non An. gambiae s.s. species were not used in these experiments. Cx. quinquefasciatus egg rafts were collected from septic tanks and polluted abandoned goldmines. Both An. gambiae s.s. eggs and $C x$. quinquefasciatus egg rafts were hatched at the same 
time and larvae of the same age-structure were used in the experimental set up.

\section{Artificial habitat preparation (Microcosms) and larvae daily monitoring}

Microcosms were made up using washing basins (diameter: 35 centimeters and depth: 15 centimeters) filled with 2 kilogrammes of soil and 3000 milliliters of rain water. These microcosms were covered with mosquito nets to prevent oviposition by other wild gravid mosquitoes. These microcosms were exposed to sunlight as found in natural habitats. Mosquito species composition in microcosms were made up of three larvae compositions i) An. gambiae s.s. alone (single species treatment), ii) An. gambiae s.s. and Cx. quinquefasciatus together (co-habitation treatment), and iii) Cx. quinquefasciatus alone (single treatment). These combinations were evaluated in the density of 20, 40, 60, 80 and 100 larvae. For the combined species (An. gambiae s.s. and Cx. quinquefasciatus), densities were made up of $50 \%$ from each species. Every density for each species and composition had ten replicates.

Age structures of surviving mosquito larvae were assessed daily; alive and dead larvae were recorded. Pupae collected from the microcosms were held in paper cups for adult emergence. When pupation started, microcosms were visited twice a day, at 8 am and $5 \mathrm{pm}$ daily for pupae collections.

Competitive advantage of the species was calculated by subtracting the total number of surviving $C x$. quinquefasciatus or An. gambiae s.s. emerged adults from the total number of surviving $C x$. quinquefasciatus and An. gambiae s.s. adults and dividing that quantity by the initial number in each cohort of both species $(n=10$, $20,30,40,50)$.

\section{Wing-length measurement}

Emergent adults were stored with silica gel until subsequent wing-length measurements. The right wing was removed and its length from the arculus to the tip (excluding the fringe) was measured using a scaled microscope. Wing-length was used as a measure of the body size because it has a high correlation to dry body weight $[34,38,39]$.

\section{Data analysis}

The Wilcoxon signed ranks test was used to compare the daily survival rates between species in co-occurrence and same species occurred alone.

The effect of co-occurrence in wing-length was analyzed using Tukey HSD test of one way analysis of variance (ANOVA) to ascertain the effect of co-occurrence on wing-length by sex and species of mosquitoes.
Mean pupation time and female and male emergence proportions were compared between co-occurrence treatment species and single species treatment species using chi-square test.

The sex ratio was calculated as the number of emerged adult females divided by the total number of emerged adults (both males and females) for each density and species. The sex ratio deviation from 0.5 within a species was calculated using test of equal proportion, Fisher's exact test.

The competitive survival advantage analysis was computed using one way analysis of variance (ANOVA) by comparing the number of adult mosquitoes emerged between the co-habitation of $A n$. gambiae s.s. and $C x$. quinquefasciastus.

\section{Results}

\section{Effect of co-occurrence on survivorship}

No effect of co-occurrence on daily survival rate was observed for either species. There was no significant difference between the survivorship in single and co-occurring treatments for all densities (Figure 1). Only at a density of 60 was there more $C x$. quinquefasciatus that survived in a single species treatment than in co-occurrence treatment (Figure 1). All larvae of each species were scored either alive or dead and none were lost during counting.

\section{Developmental Time}

There were significant differences in the pupae developmental time for each species at all densities with the single treatment developmental time being shorter than the co-habitation treatments (Figure 2A). The developmental time for male emergence for $C x$. quinquefasciatus was significantly higher in single than in cohabitation treatments at a density of 20 only; for $A n$. gambiae s.s., only the densities of $60(\mathrm{P}=0.121)$ and 80 $(\mathrm{P}=0.213)$ were not significantly different between single and co-habitation treatments co-habitation (Figure 2B). The developmental time for females $C x$. quinquefasciatus emergence in single treatment was significantly shorter than the co-habitation treatment in all densities except in larvae density of $20(\mathrm{P}=0.721)$ and $60(\mathrm{P}=$ $0.441)$; for $A n$. gambiae s.s., single treatments were significantly shorter at all densities except $20(\mathrm{P}=0.081)$ and $80(\mathrm{P}=0.067)$ where there was no difference between single and co-habitation treatments (Figure 2C).

\section{Wing-length measurements}

The overall co-occurrence significantly affected winglength for both females and males of An. gambiae s.s. as the mean wing-length in co-occuring treatment is significantly lower than in single species treatment. Co- 

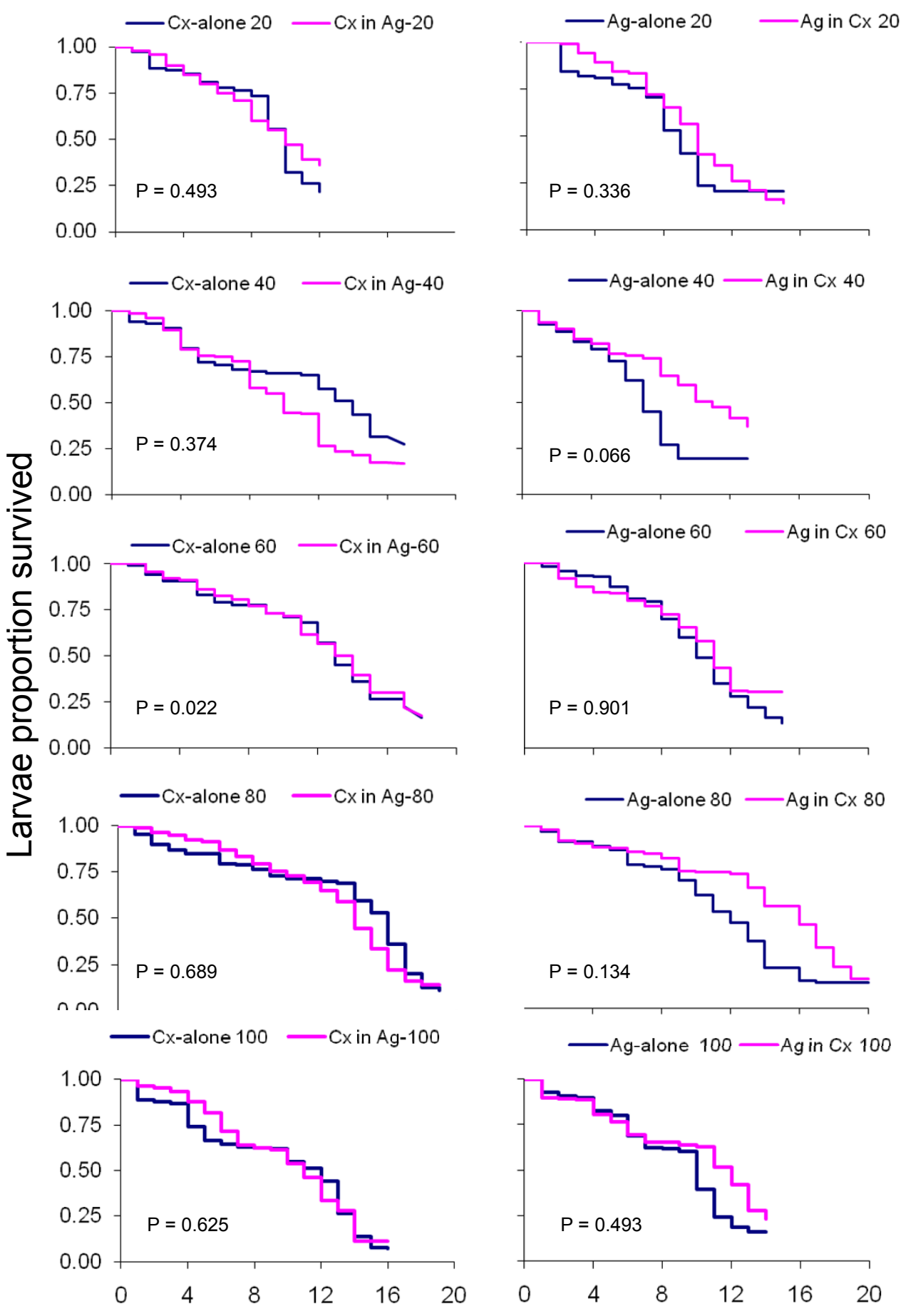

Figure 1 The comparison of daily survival rates between An. gambiae s.s (Ag) and Cx. quinquefasciatus (Cx) occurred alone and that co occurred. 


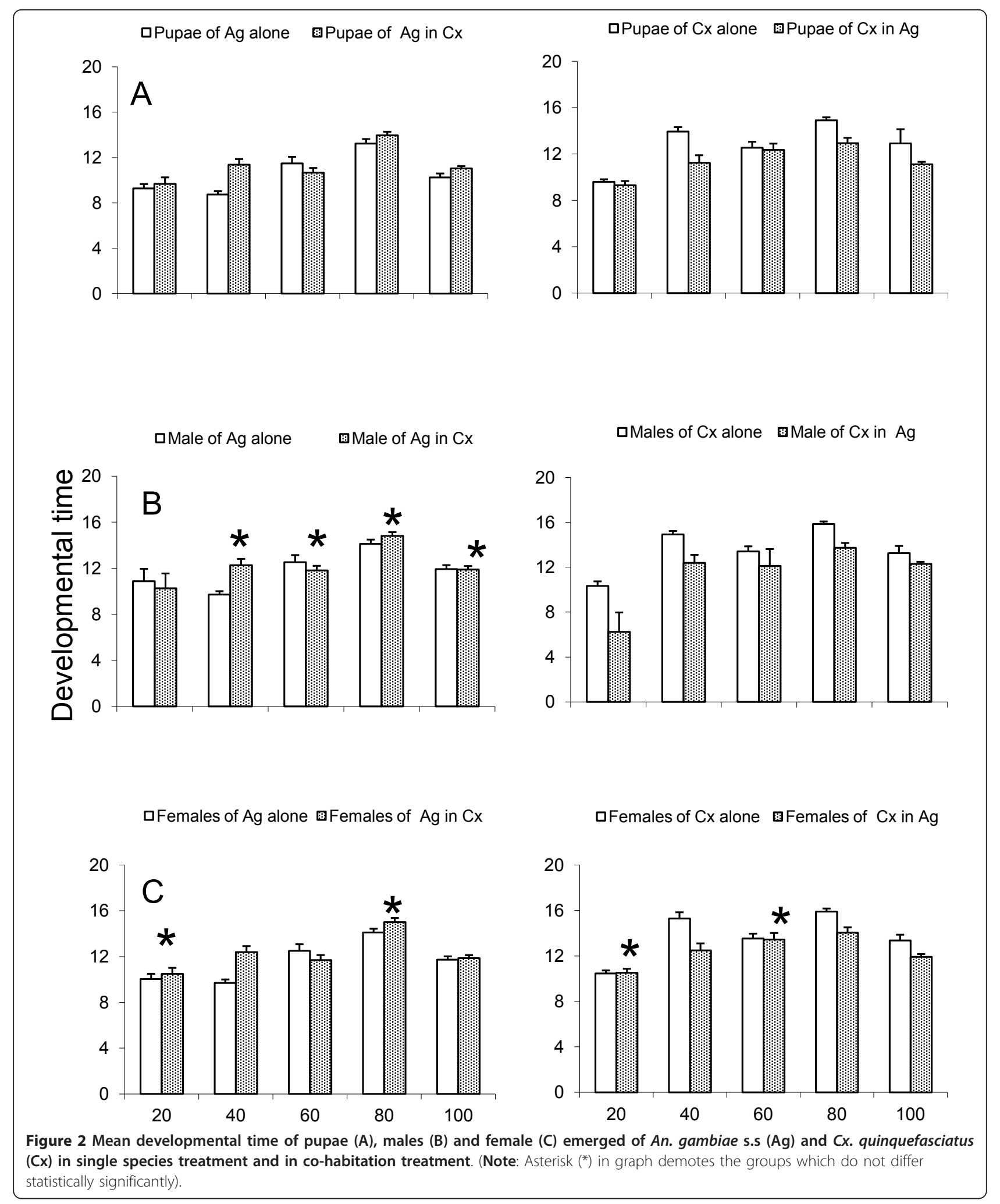




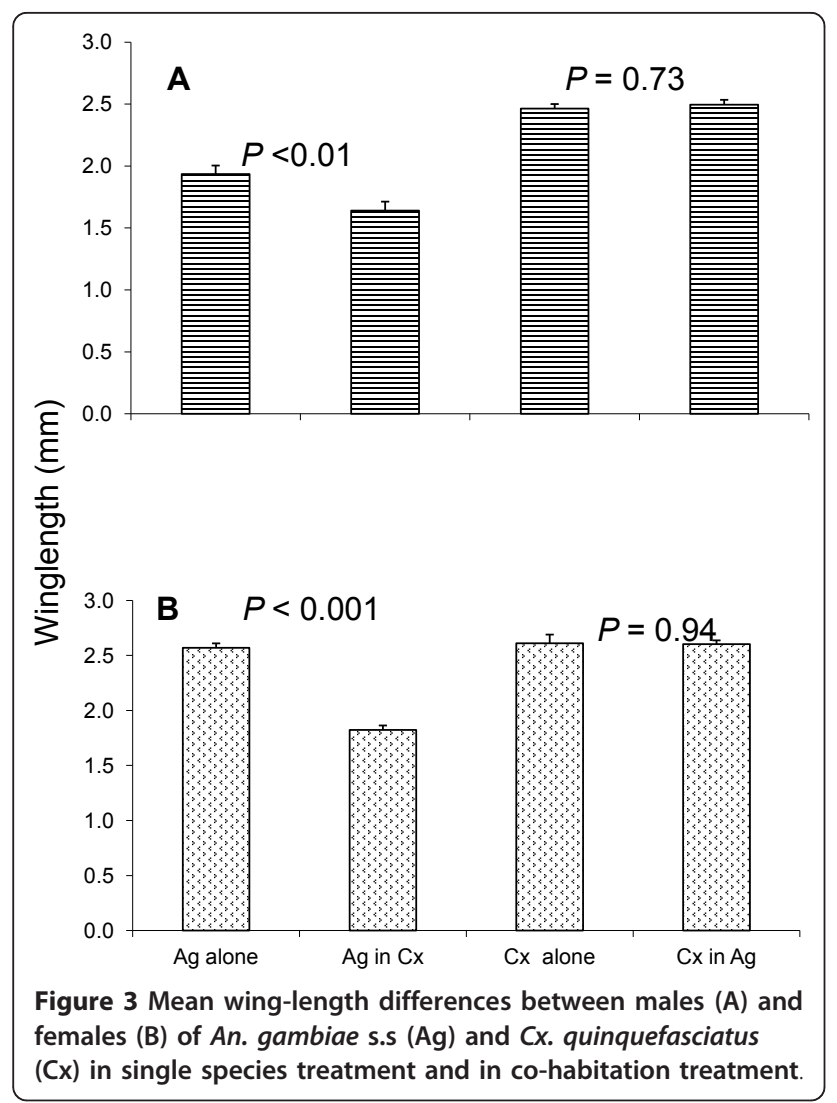

occurrence treatment had no significant effect on mean wing-length for female and male mosquitoes of $C x$. quinquefasciatus (Figure 3).

\section{Sex ratio}

The sex ratio among single species treatment of $A n$. gambiae s.s. in all larval densities was significantly lower than 0.5 and the same tendency was found in Cx. quinquefasciatus, which favoured males in both species (Table 1). The sex ratio among co-habitation An. gambiae s.s. and $C x$. quinquefasciatus was significantly different from 0.5 at densities of 20, 40 and 80 for $A n$. gambiae s.s. and at densities of 20,40, 60, and 80 for

Table 1 Sex ratio for each species in different densities among single species treatments

\begin{tabular}{lll}
\hline Density & An. gambiae s.s & Cx. quinquefasciatus \\
\hline 20 & $43.2(111)^{*}$ & $37.1(132)^{*}$ \\
\hline 40 & $33.1(260)^{*}$ & $26.1(253)^{* *}$ \\
\hline 60 & $13.9(397)^{* *}$ & $13.0(377)^{* *}$ \\
\hline 80 & $41.4(399)^{*}$ & $34.2(427)^{* *}$ \\
\hline 100 & $44.2(77)^{*}$ & $44.7(472)^{*}$ \\
\hline
\end{tabular}

Note: Sex ratios significantly different from 0.5 are indicated by ${ }^{*}$. ( $\mathrm{P}<0.05$, $\left.{ }^{* * P}<0.01\right)$. Sex ratio was calculated from the number of individuals that emerged (indicated in brackets).
Table 2 Sex ratio for each species in different densities among co-habitation treatments

\begin{tabular}{lll}
\hline Density & An. gambiae s.s & Cx. quinquefasciatus \\
\hline 20 & $64.6(96)^{*}$ & $74.5(55)^{* *}$ \\
\hline 40 & $66.1(109)^{*}$ & $63.7(124)^{*}$ \\
\hline 60 & $59.1(215)$ & $66.2(195)^{* *}$ \\
\hline 80 & $66.3(261)^{* *}$ & $67.5(277)^{* *}$ \\
\hline 100 & $62.2(172)$ & $52.5(204)$
\end{tabular}

Note: Sex ratio significantly different from 0.5 are indicated by ${ }^{*}$. $\left({ }^{*} \mathrm{P}<0.05\right.$, ${ }^{* * P}<0.01$ ). Sex ratio was calculated from the number of individuals that emerged (indicated in brackets).

Cx. quinquefasciatus (Table 2). In these cases, the sex ratio was significantly higher than 0.5 , favouring females.

\section{Competitive advantage}

At each density (i.e. 20, 40, 60, 80 and 100), there was no significant difference in the survival advantage shown by any species over another in co-habitation treatments. Also, in overall analysis, there was no significant competitive survival advantage for any species in co-habitation treatments as the mean advantage was around zero (DF $=1, \mathrm{~F}=3.7749, \mathrm{P}=0.058$ ).

\section{Discussion}

The findings of this study have demonstrated that when there is co-occurrence between An. gambiae s.s. and $C x$. quinquefasciatus in habitats with different larval densities, there are variations in different life traits. For $A n$. gambiae s.s. in co-habitation treatments, both males and females had reduced body size compared to An. gambiae s.s. in single species treatment. The sex ratio of both An. gambiae s.s. and Cx. quiquefasciatus have demonstrated a natural composition of having more males than females in single species treatment while the co-habitation treatments had more females emerging than males. Daily survival rates of An. gambiae s.s. in single and co-habitation treatments had no significant difference at any density while Cx. quiquefasciatus had similar results except at a density of 60 larvae. In developmental time, more pupae and adults were observed to emerge earlier from single species treatment than in cohabitation treatments. None of the species found were shown to have survival advantage against each other in co-habitation treatments. This study had similar and different findings compared to studies carried out elsewhere with these species of larvae co-habiting or when crowded [5,6,22,23,40-42]. Similar phenomenon of cohabitation was found to have effects within Aedes aegypti population [43,44]. An. gambiae s.s. in co-habitation treatments had no significant difference with the An. gambiae s.s. in single species treatment in daily survival rates which presumably shows that the habitats' 
resources and survivorship were dependants, and also the density used might not been enough to have the impact clearly observed in those artificial habitats resources. However, the size of the habitats and amount of food was determined to be sufficient, therefore, there was no significant difference observed in daily survivorship as outcome of resources constraints (Figure 1). In other studies, as the density of larvae increases while the amount of food and space maintained at a constant level, the survivorship was higher when the larval density was lower $[14,40]$. However, this was not the case in our study results. In co-habitation treatments, $C x$. quinquefasciatus fed on lower micro layer surfaces while $A n$. gambiae s.s. had more food sources on upper surface micro layers $[14,40]$; the difference is due to the fact that the two species have different micro layers feeding preferences in their habitats, resulting in different food sources $[29,31]$. This reveals that in species competition, when food resources and space are kept constant and larval density increase in the same species as dependant variable in limiting the survivorship of aquatic stages of mosquitoes $[11,15,30,31,41,44,45]$.

The aggregation of larvae of different species tend to produce a growth retardation chemical which limits the growth of competing species when existing in large number in a habitat [46]. In our study, the increase of larvae in both single and co-occurrence treatments had no survivorship difference but the developmental time decreases as the density increase in habitats. A similar effect was observed in studies conducted elsewhere [46].

The developmental time for An. gambiae pupae and the sex ratio of the emerged adults were found to be species and density dependant (Figure 2). The lack of significant differences in mortalities in higher densities for co-habitation treatments have shown that food sources and space in habitats had no effect on higher densities in our experiments as observed in other laboratory and field observational studies [29,31]. In the single species treatments, the sex ratio for both $A n$. gambiae s.s. and $C x$. quinquefasciatus was significantly lower than 0.5 and varied with density. This indicated that males were in higher proportions than females in single species treatments. The sex ratio among the emerged mosquitoes of each species at each density for co-habitation treatments was significantly different with higher proportion from 0.5 and varied with density in each species. This indicates that among the emerging mosquitoes, the highest proportion consisted of females rather than males. In previous studies, the adult sex ratio of female to male was 1:3 for An. gambiae s.s. [7] and 1:2 for Cx. quinquefasciatus [47]. Other observational studies done in field situations reported skewed female to male ratios ranging from 1:10 up to 1:600 during swarming $[38,48,49]$. This study has reported for the first time the effect of larvae in experimental co-habitation consisting of more females than males. These findings might have an epidemiological impact in natural populations in that, having more females than males will increase the biting rates and higher probabilities of disease transmissions; however, having fewer males in a population might cause lower fecundity and reproductive rates for female mosquitoes.

The co-habitation of An. gambiae s.s. and Cx. quinquefasciatus exists in nature $[7,8,10,11]$. In this study it was revealed that the co-habitation mostly affects $A n$. gambiae s.s. by reducing the wing-length size which is a proxy measure of the body size and the ability of host seeking and fecundity for female mosquitoes [34,50,51]. Large-bodied Aedes triseriatus females have been associated with increased parity rates (which are a measure of blood-feeding behaviour) among collected female mosquitoes [52,53]. Similar results were reported by Nasci $[53,54]$ for Psorophora columbiae (Dyar and Knab), Aedes vexans (Meigen) and Aedes aegypti (L.). Female mosquitoes that have emerged with a small body size have reduced blood meal succession hence lower fecundity and survivorship and subsequently, low parasite transmission efficiency [34,36,55-57]. In other studies, laboratory experiments have shown that female malaria vectors with small body size feed more frequently, hence this influences arbovirus transmission. For males, the body size affects flight ability which translates into reduced swarming efficiency $[42,56]$ as small males refrain from swarming for longer or begin to swarm earlier. This also means that they are less successful at mating than larger males $[42,58]$. Similar findings have been observed in An. gambiae s.s. [41,42].

The ecological life history of mosquitoes is affected mostly by larval density and food sources in habitats [31,59]. Availability of food resources in habitats determines the number of adults emerging [41], their body size [34,59], and their survivorship [41]. Crowded larvae are at a disadvantage because they are faced with greater inter and intra-specific competition for food resources and are therefore, at a risk for reduced survival [41]. They are also exposed to higher levels of toxic waste products, crowding chemicals and physical interference from other larvae $[41,60,61]$.

The competitive advantage in species was not observed to be a factor of concern in this study. Competitive displacement is based upon the ecological principle that different species sharing the same trophic level can inhibit each other from occupying the same niche $[62,63]$. Hardin [64] found that this competitive principle in various laboratory studies showed a population competition in which one of the competing species would theoretically become extinct. In An. gambiae s.s. and $C x$.quinquefasciatus co-habitation species, neither 
was found to have the competitive advantage over the other. This implies that between the two species ( $A n$. gambiae s.s. and $C x$. quinquefasciatus), neither can lead to extinction of the other in the conditions tested. In Australia, it was found that introduction of Aedes notoscriptus had led to the extinction Ae. aegypti [65].

\section{Conclusion}

These study findings suggest that the co-habitation treatment can have considerable effect on body size of An. gambiae s.s. and sex ratio of emerging adults. There is a need to explore the observed effect in natural conditions and estimate its epidemiological significance in malaria and filariasis transmission reduction and control.

\section{Conflict of interest}

The authors declare that they have no competing interests.

\section{Acknowledgements \\ Authors wish to thank Amos Wabwile and Wilberforce Onoka for monitoring the age structure of mosquito larvae throughout the study, and Paul Osodo for measuring mosquitoes' wing-length. This work had financial support from the American National Institutes of Health (D43 TW01505 and R01 Al- 50243 to GY). This paper is published with the permission of the Director General, Kenya Medical Research Institute, (KEMRI). \\ Author details \\ 'Centre for Global Health Research, Kenya Medical Research Institute, P. O. Box 1578, Kisumu 40100, Kenya. ${ }^{2}$ Kilimanjaro Christian Medical College, Tumaini University, P. O. Box 2240, Moshi, Tanzania. ${ }^{3}$ Program in Public Health, University of California, Irvine, CA 92697, USA. ${ }^{4}$ Ecology and Evolutionary Biology, University of California, Irvine, CA 92697, USA.}

\section{Authors' contributions}

EJK conceived, designed, implemented the study and supervised experiments. EJK, LB and GZ did data analysis and interpretation. EJK wrote the manuscript. EJK, GZ, LB, AD, AY, TMG, SM, MN, AKG and GY revised the manuscript. All authors approved the final version for submission.

Received: 31 October 2011 Accepted: 9 February 2012

Published: 9 February 2012

\section{References}

1. Wachira SW, Ndung'U M, Njagi PG, Hassanali A: Comparative responses of ovipositing Anopheles gambiae and Culex quinquefasciatus females to the presence of Culex egg rafts and larvae. Med Vet Entomol 2010, 24:369-374.

2. Sumba $L A$, Ogbunugafor $C B$, Deng $A L$, Hassanali $A$ : Regulation of oviposition in Anopheles gambiae s.s.: role of inter- and intra-specific signals. J Chem Ecol 2008, 34:1430-1436.

3. Service MW: Mortalities of the immature stages of species B of the Anopheles gambiae complex in Kenya: comparison between rice fields and temporary pools, identification of predators, and effects of insecticidal spraying. J Med Entomol 1977, 13:535-545.

4. Rejmankova E, Savage HM, Rejmanek M, Arredondo-Jimenez II, Roberts DR: Multivariate analysis of relationships between habitats, environmental factors and occurrence of anopheline mosquito larvae Anopheles albimanus and A. pseudopunctipennis in southern Chiapas, Mexico. J Appl Ecol 1991, 28:827-841.

5. Muturi EJ, Kim CH, Jacob B, Murphy S, Novak RJ: Interspecies predation between Anopheles gambiae s.s. and Culex quinquefasciatus larvae. J Med Entomol 2010, 47:287-290.
6. Muturi EJ, Mwangangi J, Shililu J, Muriu S, Jacob B, Kabiru E, Gu W, Mbogo C, Githure J, Novak R: Mosquito species succession and physicochemical factors affecting their abundance in rice fields in Mwea, Kenya. J Med Entomol 2007, 44:336-344.

7. Mutuku FM, Bayoh MN, Gimnig JE, Vulule JM, Kamau L, Walker ED, Kabiru E, Hawley WA: Pupal habitat productivity of Anopheles gambiae complex mosquitoes in a rural village in western Kenya. Am J Trop Med Hyg 2006, 74:54-61.

8. Munga S, Minakawa N, Zhou G, Mushinzimana E, Barrack OO, Githeko AK, Yan G: Association between land cover and habitat productivity of malaria vectors in western Kenyan highlands. Am J Trop Med Hyg 2006, 74:69-75.

9. Minakawa N, Sonye G, Mogi M, Yan G: Habitat characteristics of Anopheles gambiae s.s. larvae in a Kenyan highland. Med Vet Entomol 2004, 18:301-305.

10. Kweka EJ, Zhou G, Lee MC, Gillbreath TM, Mosha F, Munga S, Githeko AK, Yan G: Evaluation of two methods of estimating larval habitat productivity in western Kenya highlands. Parasit Vectors 2011, 4:110.

11. Mwangangi JM, Muturi EJ, Shililu J, Muriu SM, Jacob B, Kabiru EW, Mbogo CM, Githure J, Novak R: Contribution of different aquatic habitats to adult Anopheles arabiensis and Culex quinquefasciatus (Diptera: Culicidae) production in a rice agroecosystem in Mwea, Kenya. J Vector Ecol 2008, 33:129-138.

12. Schneider P, Takken W, McCall PJ: Interspecific competition between sibling species larvae of Anopheles arabiensis and An. gambiae. Med Vet Entomol 2000, 14:165-170.

13. Kessler S, Guerin PM: Responses of Anopheles gambiae, Anopheles stephensi, Aedes aegypti, and Culex pipiens mosquitoes (Diptera: Culicidae) to cool and humid refugium conditions. J Vector Ecol 2008, 33:145-149.

14. van de Wolfshaar KE, de Roos AM, Persson L: Size-dependent interactions inhibit coexistence in intraguild predation systems with life-history omnivory. Am Nat 2006, 168:62-75.

15. Reiskind $\mathrm{MH}$, Walton $\mathrm{ET}$, Wilson ML: Nutrient-dependent reduced growth and survival of larval Culex restuans (Diptera: Culicidae): laboratory and field experiments in Michigan. J Med Entomol 2004, 41:650-656.

16. Legros M, Lloyd AL, Huang Y, Gould F: Density-dependent intraspecific competition in the larval stage of Aedes aegypti (Diptera: Culicidae): revisiting the current paradigm. J Med Entomol 2009, 46:409-419.

17. Gross A, Kiszkaa J, Van Canneyt O, Richard P, Ridoux V: A preliminary study of habitat and resource partitioning among co-occurring tropical dolphins around Mayotte, southwest Indian Ocean. Estuarine, Coastal and Shelf Science 2009, 84:367-374.

18. Shigesada N, Kawasaki K, Teramoto E: Direct and indirect effects of invasions of predators on a multiple-species community. Theoretical Popul Biol 1989, 36:311-338.

19. Kaplan I, Denno RF: Interspecific interactions in phytophagous insects revisited: a quantitative assessment of competition theory. Ecol Lett 2007, 10:977-994.

20. Paini DR, Funderburk JE, Reitz SR: Competitive exclusion of a worldwide invasive pest by a native. Quantifying competition between two phytophagous insects on two host plant species. J Anim Ecol 2008, 77:184-190.

21. Reitz SR, Trumble JT: Competitive displacement among insects and arachnids. Annu Rev Entomol 2002, 47:435-465.

22. Koenraadt CJ, Takken W: Cannibalism and predation among larvae of the Anopheles gambiae complex. Med Vet Entomol 2003, 17:61-66.

23. Koenraadt CJ, Majambere S, Hemerik L, Takken W: The effects of food and space on the occurrence of cannibalism and predation among larvae of Anopheles gambiae s.l. Entomol Experimentalis et Applicata 2004, 112:125-134.

24. Aditya G, Bhattacharyya S, Kundu N, Kar PK, Saha GK: Predatory efficiency of the sewage drain inhabiting larvae of Toxorhynchites splendens Wiedemann on Culex quinquefasciatus Say and Armigeres subalbatus (Coquillett) larvae. Southeast Asian J Trop Med Public Health 2007, 38:799-807.

25. Focks DA: Toxorhynchites as biocontrol agents. J Am Mosq Control Assoc 2007, 23:118-127.

26. Padgett PD, Focks DA: Laboratory observations on the predation of Toxorhynchites rutilus rutilus on Aedes aegypti (Diptera: Culicidae). J Med Entomol 1980, 17:466-472. 
27. Schreiber ET: Toxorhynchites. J Am Mosq Control Assoc 2007, 23:129-132.

28. lyengar MOT: Preliminary report of a malaria survey of Calcutta and environs Indian Science Congress No. 8-111. Appl Entomol B 1920, 9:124.

29. Jin L, Luo J, Fu Y, Xu S: Prey and feeding behavior of larval Culex (Lutzia) fuscanus (Diptera: Culicidae) in Shantou, Guangdong Province, China. J Med Entomol 2006, 43:785-786.

30. Arsic D, Guerin PM: Nutrient content of diet affects the signaling activity of the insulin/target of rapamycin/p70 S6 kinase pathway in the African malaria mosquito Anopheles gambiae. J Insect Physiol 2008, 54:1226-1235.

31. Gimnig JE, Ombok M, Otieno S, Kaufman MG, Vulule JM, Walker ED: Density-dependent development of Anopheles gambiae (Diptera: Culicidae) larvae in artificial habitats. J Med Entomol 2002, 39:162-172.

32. Merritt RW, Craig DA: Larval mosquito (Diptera: Culicidae) feeding mechanisms: mucosubstance production for capture of fine particles. $J$ Med Entomol 1987, 24:275-278.

33. Lounibos LP, Nishimura N, Conn J, Lourenco-de-Oliveira R: Life history correlates of adult size in the malaria vector Anopheles darlingi. Mem Inst Oswaldo Cruz 1995, 90:769-774.

34. Lyimo EO, Koella JC: Relationship between body size of adult Anopheles gambiae s.l. and infection with the malaria parasite Plasmodium falciparum. Parasitology 1992, 104:233-237.

35. Peacor SD, Werner EE: The contribution of trait-mediated indirect effects to the net effects of a predator. Proc Natl Acad Sci USA 2001, 98:3904-3908.

36. Lyimo EO, Takken W: Effects of adult body size on fecundity and the pregravid rate of Anopheles gambiae females in Tanzania. Med Vet Entomol 1993, 7:328-332.

37. Scott JA, Brogdon WG, Collins FH: Identification of single specimens of the Anopheles gambiae complex by the polymerase chain reaction. Am J Trop Med Hyg 1993, 49:520-529.

38. Clements AN: The Biology of Mosquitoes, Vol. I, Development, Nutrition and Reproduction. Chapman \& Hall, London; 1992.

39. Koella JC, Lyimo EO: Variability in the relationship between weight and wing length of Anopheles gambiae (Diptera: Culicidae). J Med Entomol 1996, 33:261-264.

40. Ng'habi KR, John B, Nkwengulila G, Knols BG, Killeen GF, Ferguson HM: Effect of larval crowding on mating competitiveness of Anopheles gambiae mosquitoes. Malar J 2005, 4:49.

41. Ye-Ebiyo Y, Pollack RJ, Kiszewski A, Spielman A: Enhancement of development of larval Anopheles arabiensis by proximity to flowering maize (Zea mays) in turbid water and when crowded. Am J Trop Med Hyg 2003, 68:748-752.

42. Yuval B, Wekesa JW, Washino RK: Effect of body size on swarming behavior and mating success of male Anopheles freeborni (Diptera: Culicidae). Journal of Insect Behavior 1993, 6:333-342.

43. Briegel H, Kaiser C: Life-span of mosquitoes (Culicidae, Diptera) under laboratory conditions. Gerontologia 1973, 19:240-249.

44. Briegel H, Knusel I, Timmermann SE: Aedes aegypti: size, reserves, survival, and flight potential. J Vector Ecol 2001, 26:21-31.

45. Silver JB: Estimation of the Mortalities of the Immature Stages. Mosquito Ecology Springer Netherlands; 2008, 1049-1160.

46. Nekrasova LS: Experimental Study on the Effects of Population Density of Bloodsucking Mosquito (Aedes communis Deg.) Larvae on Their Biological Characteristics. Russian J of Ecol 2004, 35:194-199.

47. Aigbodion Fl, Nnoka HC: A comparative study of the activities of Anopheles gambiae, Culex quinquefasciatus and Aedes aegypti (Diptera: Culicidae) by pyrethrum spray collection in Benin City, Nigeria. Bioscience Research Communications 2008, 20:147-151.

48. Charlwood JD, Jones MDR: Mating behaviour in the mosquito,Anopheles gambiae s.l. II. Swarming behaviour. Physiol Entomol 1980, 5:315-320.

49. Reisen WK, Aslam Y, Siddiqui TF: Observation on the swarming and mating of some Pakistan mosquitoes in nature. Ann Entomol Soc Am 1977, 70:988-995.

50. Fernandes L, Briegel H: Reproductive physiology of Anopheles gambiae and Anopheles atroparvus. J Vector Ecol 2005, , 30: 11-26.

51. Takken W, Klowden MJ, Chambers GM: Effect of body size on host seeking and blood meal utilization in Anopheles gambiae sensu stricto (Diptera: Culicidae): the disadvantage of being small. J Med Entomol 1998, 35:639-645.
52. Haramis LD, Foster WA: Survival and population density of Aedes triseriatus (Diptera: Culicidae) in a woodlot in central Ohio, USA. J Med Entomol 1983, 20:391-398.

53. Nasci RS: Biology of Aedes triseriatus (Diptera: Culicidae) developing in tires in Louisiana. J Med Entomol 1988, 25:402-405.

54. Nasci RS: Toxorhynchites rutilus septentrionalis feeding on tree sap. J Am Mosa Control Assoc 1986, 2:559.

55. Cohuet A, Harris C, Robert V, Fontenille D: Evolutionary forces on Anopheles: what makes a malaria vector? Trends Parasitol 2010, 26:130-136.

56. Kaufmann C, Briegel $\mathrm{H}$ : Flight performance of the malaria vectors Anopheles gambiae and Anopheles atroparvus. J Vector Ecol 2004 29:140-153.

57. Naksathit AT, Scott TW: Effect of female size on fecundity and survivorship of Aedes aegypti fed only human blood versus human blood plus sugar. J Am Mosa Control Assoc 1998, 14:148-152.

58. Yuval B, Bouskila A: Temporal dynamics of mating and predation in mosquito swarms. Oecologia 1993, 95:65-69.

59. Schneider JR, Morrison AC, Astete H, Scott TW, Wilson ML: Adult size and distribution of Aedes aegypti (Diptera: Culicidae) associated with larval habitats in lquitos, Peru. J Med Entomol 2004, 41:634-642.

60. Frouz J, Lobinske R, Ali A: Intraspecific competition of Glyptotendipes paripes (Diptera: Chironomidae) larvae under laboratory conditions. Aquatic Ecol 2009, 43:487-500.

61. Juliano SA, Lounibos LP, O'Meara GF: A field test for competitive effects of Aedes albopictus on A. aegypti in South Florida: differences between sites of coexistence and exclusion? Oecologia 2004, 139:583-593.

62. DeBach P: The competitive displacement and coexistence principles. Ann Rev Entomol 1966, 11:183-212.

63. Venner S, Pelisson PF, Bel-Venner MC, Debias F, Rajon E, Menu F: Coexistence of insect species competing for a pulsed resource: toward a unified theory of biodiversity in fluctuating environments. PLOS One 2011, 6:e18039.

64. Hardin G: The competitive exclusion principle. Science 1960, 131:1292-1297.

65. Russell RC: Larval Competition between the Introduced Vector of Dengue Fever in Australia, Aedes aegypti (L.), and a Native ContainerBreeding Mosquito,Aedes notoscriptus (Skuse) (Diptera: Culicidae). Aust J Zool 1986, 34:527-534.

doi:10.1186/1756-3305-5-33

Cite this article as: Kweka et al:: Effects of co-habitation between Anopheles gambiae s.s. and Culex quinquefasciatus aquatic stages on life history traits. Parasites \& Vectors 2012 5:33.

\section{Submit your next manuscript to BioMed Central and take full advantage of:}

- Convenient online submission

- Thorough peer review

- No space constraints or color figure charges

- Immediate publication on acceptance

- Inclusion in PubMed, CAS, Scopus and Google Scholar

- Research which is freely available for redistribution

Submit your manuscript at www.biomedcentral.com/submit
C Biomed Central 